\title{
Risk factors for lameness in freestall-housed dairy cows across two breeds, farming systems, and countries
}

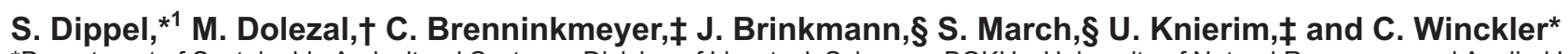 \\ *Department of Sustainable Agricultural Systems, Division of Livestock Sciences, BOKU—University of Natural Resources and Applied Life \\ Sciences Vienna, Gregor-Mendel-Strasse 33, 1180 Vienna, Austria \\ †Institut für Populationsgenetik, University of Veterinary Medicine Vienna, Josef Baumanngasse 1, 1210 Vienna, Austria \\ $\ddagger$ Department of Farm Animal Behaviour and Husbandry, FB 11, University of Kassel, Nordbahnhofstraße 1a, 37213 Witzenhausen, Germany \\ §Georg-August-University of Göttingen, Department of Animal Sciences, Location Vechta, Driverstrasse 22, 49377 Vechta, Germany
}

\begin{abstract}
Lameness poses a considerable problem in modern dairy farming. Several new developments (e.g., herd health plans) strive to help farmers improve the health and welfare of their herd. It was thus our aim to identify lameness risk factors common across regions, breeds, and farming systems for freestall-housed dairy cows. We analyzed data from 103 nonorganic and organic dairy farms in Germany and Austria that kept 24 to 145 Holstein Friesian or Fleckvieh cows in the milking herd (mean $=48$ ). Data on housing, management, behavior, and lameness scores for a total of 3,514 cows were collected through direct observations and an interview. Mean lameness prevalence was 34\% (range = 0-81\%). Data were analyzed applying logistic regression with generalized estimating equations in a split-sample design. The final model contained 1 animal-based parameter and 3 risk factors related to lying as well as 1 nutritional animal-based parameter, while correcting for the significant confounders parity and data subset. Risk for lameness increased with decreasing lying comfort, that is, more frequent abnormal lying behavior, mats or mattresses used as a stall base compared with deep-bedded stall bases, the presence of head lunge impediments, or neck rail-curb diagonals that were too short. Cows in the lowest body condition quartile (1.25-2.50 for Holstein Friesian and 2.50-3.50 for Fleckvieh) had the highest risk of being lame. In crossvalidation the model correctly classified 71 and $70 \%$ of observations in the model-building and validation samples, respectively. Only 2 out of 15 significant odds ratios (including contrasts) changed direction. They pertained to the 2 variables with the highest $P$-values in the model. In conclusion, lying comfort and nutrition are key risk areas for lameness in freestall-housed dairy cows. Abnormal lying behavior in particular proved to
\end{abstract}

Received April 10, 2009.

Accepted August 5, 2009.

${ }^{1}$ Corresponding author: s.dippel@web.de be a good predictor of lameness risk and should thus be included in on-farm protocols. The study is part of the European Commission's Welfare Quality ${ }^{\circledR}$ project.

Key words: lameness, dairy cow, risk factor, generalized estimating equation

\section{INTRODUCTION}

Fertility problems, mastitis, and lameness are the top 3 production diseases in dairy cows (Bennett et al., 1999). Lameness causes financial losses to the farmer and considerably reduces the welfare of a cow because it is associated with painful conditions in the locomotory apparatus (Whay et al., 1997). Many cows have lesions in their feet without altering their gait (Manske et al., 2002); these cows might suffer from pain without showing it. While the painfulness and effect of different types of claw lesions on production are not clear, lame cows certainly suffer from pain and have reduced production (Warnick et al., 2001; Amory et al., 2008).

Lameness prevalence varies considerably between farms and regions; Winckler and Brill (2004), for example, reported a lameness prevalence range of 25 to $58 \%$. Furthermore, the type of farming system used has an influence; lameness prevalence is usually lower on organic farms because of more extensive production (Rutherford et al., 2009). The strongest impact on lameness prevalence, however, is the specific combination of risk factors on a given farm. There is a large range of factors that could potentially increase risk of lameness, including the implementation of claw trimming (Manson and Leaver, 1988), deep litter versus cubicle housing (Webster, 2001), access to pasture (Hernandez-Mendo et al., 2007), social rank (Galindo et al., 2000), and predisposing physiological stages such as parturition and lactation (Knott et al., 2007). Strong effects of nutrition have also been found repeatedly (e.g., Manson and Leaver, 1988). Experiments with respect to lying behavior, on the other hand, are scarce and sometimes yield contradictory results (Leonard et al., 1994; Galindo and Broom, 2000). 
Table 1. Farm characteristics [median (minimum, maximum)] for data subsets A, O, and G and the complete data set (ALL)

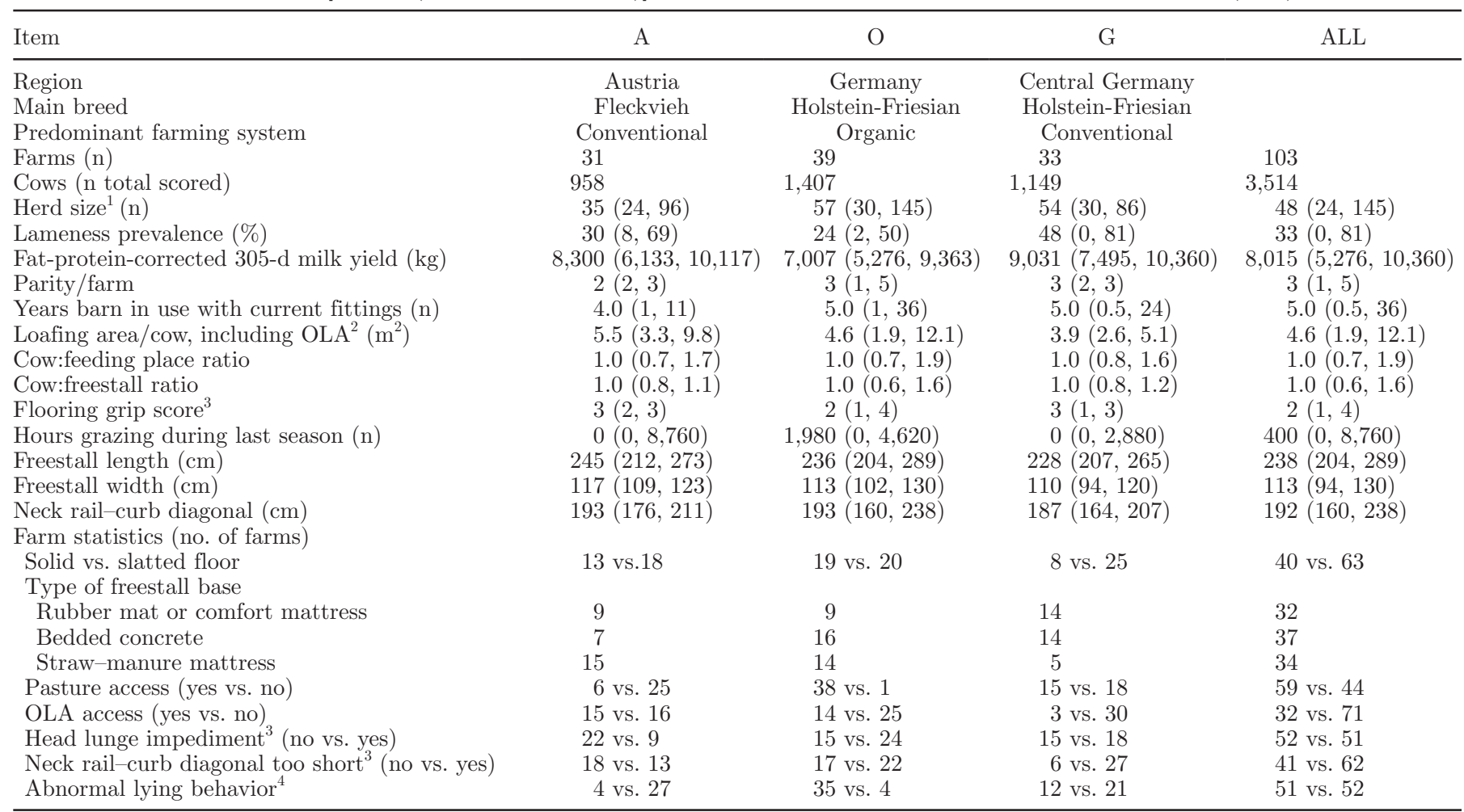

${ }^{1}$ Number of animals in milking herd, including nonmilking transition cows and heifers.

${ }^{2} \mathrm{OLA}=$ outdoor loafing area.

${ }^{3}$ See text for definition.

${ }^{4}$ See text for definition; less than vs. more than overall farm median.

Increased awareness of lameness as a problem and the development of herd health plans in the United Kingdom (Bell et al., 2006) raised the question of key risk areas on farms (i.e., areas that should always be included in farm assessment). Most publications regarding epidemiology of lameness investigate lameness only in similar groups of farms. Our objective was to identify risk factors for lameness that are common across a broad range of farms.

\section{MATERIALS AND METHODS}

\section{Study Design and Population}

We analyzed data from 103 dairy farms with freestall housing in Austria and Germany during the winter housing period from 2004 to 2005 (starting in December 2004). Farms were grouped into 3 data subsets differing with respect to region, farming system, and predominant breed (Table 1). One data subset $(\mathbf{G})$ was made up of conventional dairy farms in central Germany milking Holstein Friesian (HF) cows with a reportedly high lameness prevalence (overall mean $=45 \%$; Winckler and Brill, 2004). The second data subset (O) consisted of organic dairy farms with HF cows from all over Germany (mean reported lameness prevalence $=18 \%$; Brinkmann and Winckler, 2004). The third data subset (A) represented conventional dairy farms in Austria with dual-purpose Fleckvieh (FV) as the predominant breed (mean reported lameness prevalence $=36 \%$; Mülleder and Waiblinger, 2004). Farms in data subsets $A$ and $G$ were visited by 1 observer each, whereas farms in subset $\mathrm{O}$ were visited jointly by 2 observers.

All barns had been in use for more than $1 \mathrm{yr}$ with the current fittings, except on 3 farms. On one farm freestall dimensions had been changed 6 mo previously, on the second farm automatic feed barriers for feeding concentrate had been installed 8 mo previously, and on the third farm nipple drinkers had been replaced by a water trough 11 mo previously. In all 3 cases, we judged the time between changes and farm visits to be long enough to allow for effects of the altered equipment to show in animal-based parameters. None of the barns had rubber flooring.

The number of animals in the milking herd (referred to as herd size below) ranged from 24 to 145 (median = 
Table 2. Scoring key used for locomotion assessment (modified from Winckler and Willen, 2001)

\begin{tabular}{lcl}
\hline Lameness category & Score & Description \\
\hline Not lame & 1 & Normal gait \\
Lame & 2 & Uneven gait (stiff, very careful, swinging around udder, swaying with body) \\
& 3 & Short striding gait with 1 limb (even if just noticeable) \\
& 4 & Short striding gait with more than 1 limb or strong reluctance to bear weight on 1 limb \\
& 5 & Does not support on 1 limb or strong reluctance to put weight on limb in 2 or more limbs, \\
& holding a limb up whenever possible \\
\hline
\end{tabular}

48). All farms were members of performance recording agency and complied with certain criteria, such as uniformity of housing equipment (e.g., no mix of freestall or flooring types in milking herd). Herds were not visited in the case of peak occurrences of painful digital or interdigital dermatitis stages or if more than $50 \%$ of the animals had been trimmed within the past $4 \mathrm{wk}$. Single animals that had been trimmed within that period were excluded from examination. Average overall lameness prevalence was $34 \%$ and average prevalence of severe lameness was $16 \%$.

\section{Interobserver Agreement}

Observers met 3 times before and once after farm visits for data collection training and to test agreement on BCS and gait scores. We used prevalence-adjusted bias-adjusted kappas (PABAK) for each observer pair as measures of agreement, which we interpreted as follows: PABAK $\geq 0.75=$ excellent agreement, 0.4 to $0.75=$ fair to good agreement, and $<0.4=$ poor agreement.

Interobserver agreement for lame versus not lame (see Table 2 for definition) was excellent in $17 \%$ and fair to good in $83 \%$ of all tests. Mean PABAK before data collection was 0.58 (range $=0.49-0.68 ; \mathrm{n}=135-150$ ) and after data collection was 0.70 (range $=0.44-0.88$; $\mathrm{n}=50-144$; see also Brenninkmeyer et al., 2007). The PABAK for BCS ranged from 0.65 to 0.95 .

\section{Data Collection on Farm and Data Management}

Each farm was visited during 1 afternoon and the consecutive morning. Data collection included locomotion and body condition scoring in a sample of lactating cows, assessment of the dimensions and quality of the housing environment, and lying behavior observations. In addition, farmers were interviewed about their herd management (e.g., how and how often the floor and cubicles were cleaned, feeding ration, hoof care, and use of calving pen; questionnaire and data collection protocol available on request). Milk recording data from the monthly reports that were closest to the farm visit were retrieved directly from the performance recording agen- cies. The recommended range for fat:protein ratio was defined as 1.0 to 1.5 inclusively, the recommended range for protein was defined as 3.2 to $3.8 \%$, and the recommended range for urea was defined as 150 to $300 \mathrm{mg} /$ $\mathrm{kg}$ (Jeroch et al., 1999). All quality scores had integer values and were combined into median farm values.

Flooring and Space Allowance. Flooring grip was scored subjectively by standing with bent knees and weight evenly distributed, using the same rubber boots on every farm. Scores ranged from very slippery (score $0=$ no grip when braking, very easy spinning) to rough (score $4=$ sliding and spinning not possible, coarse and abrasive surface). The number of ridges, holes, and so on in each functional zone (e.g., main and feed alleys, parlor) was used as a measure of flooring quality (variable for analysis $=$ more than 5 such items present, yes vs. no). Space allowance in the loafing area, both including and excluding outdoor loafing areas, was collapsed into binary variables by using the median over all farms as the threshold (Table 3).

Freestalls. Stall measurements were taken from at least 2 representative stalls, depending on variation in stall dimensions. If the stalls were both face-to-face as well as facing a wall, at least 2 from each kind were measured. On 2 farms, only 1 stall of a kind was measured because the respective set contained few and very uniform stalls.

We compared the diagonal distance between the neck rail and curb as well as the lunging space with recommendations based on animal size. The respective sizes were obtained by measuring subsamples of $364 \mathrm{HF}$ and $295 \mathrm{FV}$ cows. To ensure appropriate dimensions for $90 \%$ of cows in the herd, we used $90 \%$ quantiles of measurements. The $90 \%$ quantile for height at withers $(\mathbf{H W})$ was $148 \mathrm{~cm}$ for $\mathrm{HF}$ and $143 \mathrm{~cm}$ for $\mathrm{FV}$, and the $90 \%$ quantile for rump diagonal (RD) was $171 \mathrm{~cm}$ and $170 \mathrm{~cm}$ for $\mathrm{HF}$ and $\mathrm{FV}$, respectively.

Neck rail-curb diagonals were defined as too short when in at least 1 of the sampled stalls the distance from the end of the bed or the inner side of curb to the lower side of the neck rail was shorter than the square root of $\left.\left[(0.92 \times \mathrm{RD})^{2}+(0.75 \times \mathrm{HW})^{2}\right]\right\} \mathrm{cm}$ (modified from Winckler and Knierim, 2004a). Head lunge impediment was considered to be present in any 
Table 3. Distribution of farm-level factors collapsed into binary variables by overall median or into categorical variables by quartiles ${ }^{1}$

\begin{tabular}{|c|c|c|c|c|c|}
\hline Factor & Minimum & $25 \%$ & Median & $75 \%$ & Maximum \\
\hline Abnormal lying behavior ${ }^{2}$ & 0.00 & & 0.01 & & 0.57 \\
\hline Median duration of lying- & & & & & 64 \\
\hline & $\begin{array}{l}3.61 \\
0.75\end{array}$ & & $\begin{array}{l}5.09 \\
1.50\end{array}$ & & $\begin{array}{l}6.4 \\
3.00\end{array}$ \\
\hline Loafing area/cow, including $\mathrm{OLA}^{4}\left(\mathrm{~m}^{2}\right)$ & 1.9 & & 4.6 & & 12.1 \\
\hline Loafing area/cow, barn only $\left(\mathrm{m}^{2}\right)$ & 1.6 & & 3.9 & & 8.2 \\
\hline BCS Holstein-Friesian cows & 1.25 & 2.50 & 2.75 & 3.25 & 4.50 \\
\hline BCS Fleckvieh cows & 2.50 & 3.75 & 4.00 & 4.25 & 5.00 \\
\hline Bedding height $(\mathrm{cm})$ & 0 & 0 & 1 & 3 & 12 \\
\hline Concentrate fed ( $\mathrm{kg} / \mathrm{kg}$ of milk) & 0.0 & 0.2 & 0.2 & 0.2 & 0.4 \\
\hline Herd size $(n)$ & 24 & 36 & 48 & 62 & 145 \\
\hline
\end{tabular}

${ }^{1}$ Data from 3,258 cows from 103 loose-housing dairy farms in Austria and Germany.

${ }^{2}$ Average frequency/cow in $2 \mathrm{~h}$.

${ }^{3} \mathrm{BCS}=5$-score key with 0.25 -unit intervals.

${ }^{4} \mathrm{OLA}=$ outdoor loafing area.

of 3 conditions: 1) the brisket board height was $>30 \mathrm{~cm}$ (Winckler and Knierim, 2004b); 2) the front rail was between $30 \mathrm{~cm}$ and $(0.55 \times \mathrm{HW}) \mathrm{cm}$ high and the stall was shorter than $(0.92 \times \mathrm{RD}+15+0.56 \times \mathrm{HW})$ $\mathrm{cm}$ (Winckler and Knierim, 2004a); or 3) the front rail was at the latter height and the horizontal distance between the brisket board and the rail was $<69 \mathrm{~cm}$ (Cook, 2005). Stall width was not used because of its lack in variation (Table 1 ).

Lying Behavior. Lying behavior was observed during $2 \mathrm{~h}$ in the afternoon and, in some cases, in the evening. Average frequency of abnormal lying behavior per cow in the milking herd within $2 \mathrm{~h}$ was recorded using continuous behavior sampling. Abnormal lying behavior included interrupted lying down and rising movements, lying down or rising lasting longer than 20 s, reversed lying (lying down with hindquarters first), horse-like rising (rising with forequarters first), and dog-like sitting (sitting on hindquarters like a dog). The total durations of 4 to 43 (mean $=19)$ lying-down movements were recorded with a stop watch on all but 1 farm, where no such movements were observed. A movement was measured from bending the first front leg until the cow had reached its final lying position. Rising was also recorded but there were too few valid observations on several farms. Lying-down movements that took longer than $20 \mathrm{~s}$ were recorded as " $20 \mathrm{~s}$ " and were included as such in farm median calculations. Abnormal lying behavior and lying-down movements were collapsed into binary variables using the farm median as a threshold (Table 3 ).

Body Condition and Locomotion. Body condition was assessed, while cows were fixed in the feed rack, using a 5-score key with 0.25-unit intervals (Metzner et al., 1993; Jilg and Weinberg, 1998). The BCS range on each farm was transformed into a binary variable by using the median over all farms as threshold (Table 3). At animal level, BCS were coded in a 4-level categorical variable based on quartiles by breed. Body condition score quartiles for HF were first $=1.25$ to 2.50 , second $=2.75$, third $=3.00$ to 3.25 , and fourth $=3.25$ to 4.50 ; $\mathrm{BSC}$ quartiles for $\mathrm{FV}$ were first $=2.50$ to 3.50 , second $=3.75$, third $=4.00$, and fourth $=4.25$ to 5.00. After BCS scoring, cows were released one by one and their locomotion was scored following Winckler and Willen (2001; Table 2). During gait assessment, cows walked along the alleys inside the barn at their own speed. The observer followed behind and, if needed, encouraged the cow by calling or gently nudging to make her walk continuously. Gait scores were transformed into binary lameness scores by classifying scores 1 and 2 as not lame and scores 3 to 5 as lame (Table 2).

In herds with up to 30 lactating animals present, all animals were scored. In larger herds sample size was based on Dohoo et al. (2003), resulting in 22 to 52 $($ mean $=34)$ cows being scored per farm. Cows were selected randomly in the feed rack, in the milking parlor, or from a list. Nonlactating animals in the milking herd and cows in sick pens were excluded.

\section{Data Management and Analysis}

Data quality with respect to errors, missing values, variable distribution, and outliers was assured using descriptive statistics (PROC FREQ and PROC UNIVARIATE) in SAS (version 9.1.3; SAS Institute, 2008). All continuous variables that did not satisfactorily cover the whole range of measurements were categorized such that at least $20 \%$ of observations fell in each class. If this was not possible, the variable was excluded from analysis. The latter was the case for transition feeding in the strict sense of gradually changing forage and 
concentrate over more than $21 \mathrm{~d}$ (applied on only $7 \%$ of farms) and routine claw trimming, which was implemented at least once per year by $85 \%$ of farms overall and all farms in data subset A. The factors BCS, parity, and fat:protein ratio were kept because we considered them to be important factors even though only $19 \%$ of observations fell in a class.

Several cows had to be excluded after locomotion scoring because of events unknown at the time of scoring that interfered with locomotion (e.g., single animal claw trimmed less than $4 \mathrm{wk}$ prior, or animal acquired less than 1 yr prior). Cows with more than 650 DIM were also excluded, resulting in a data set with 3,258 cows.

Finally, the data set was split into a model-building sample (MOD) containing $85 \%$ of observations of each farm ( $\mathrm{n}=2,720$ cows), and a cross-validation sample (VAL) with $15 \%$ of observations $(\mathrm{n}=538)$ (PROC SURVEYSELECT, METHOD $=$ SRS, STRATA = farm). Mean lameness prevalence was 34\% overall before splitting and $33 \%$ and $36 \%$ in sample data sets MOD and VAL, respectively.

\section{Logistic Regression}

We calculated logistic regression models with generalized estimating equations (GEE; Liang and Zeger, 1986) with compound symmetry covariance structure (Dohoo et al., 2003) using the REPEATED statement and logit link function in PROC GENMOD in SAS (version 9.1.3; SAS Institute, 2008). Compound symmetry matrices and GEE account for the data set covariance structure of correlated measurements (cows within the same farm; Dohoo et al., 2003; SAS Institute, 2008).

Identification of statistically significant risk factors comprised several steps, all of which were performed with sample data set MOD. First, all variables in Table 4 were screened for their univariate association with the outcome, using a Wald statistic $P$-value $\leq 0.2$ as a threshold (SAS option WALD, version 9.1.3; SAS Institute, 2008).

Second, factors that had a significant univariate association were clustered by area of influence, and variance inflation factors (VIF) were calculated for each cluster using PROC REG in SAS (version 9.1.3; SAS Institute, 2008). During the entire modeling process, only variables with VIF lower than 2.5 were allowed in the model to control for collinearity. From this step onwards, data subset and parity were forced into all models as confounding variables.

After manual backward selection within each cluster using a significance threshold of $P_{\text {Wald }} \leq 0.05$, all significant variables in a particular cluster were combined into 1 model that was also backward selected. The result- ing overall model formed the base for manual stepwise selection $\left(P_{\text {Wald }} \leq 0.05\right)$ from all variables not included in the model. All remaining variables were retested one by one in the model and the variable with the lowest $P_{\text {Wald }}$ was added. After each variable inclusion, any variables with $P_{\text {Wald }}>0.05$ were removed before new variables were tested. The procedure was stopped when no significant variable could be entered without causing collinearity problems.

Finally, the remaining variables were evaluated for confounding in the form of estimate changes greater than $30 \%$ in variables of interest (Dohoo et al., 2003) by adding the possible confounders one by one to the model. No such changes were caused and no variables were added to the model. Interactions were not estimated because they made the model unstable. $P$-values for least squares means differences were step-down Bonferroni-corrected.

\section{RESULTS}

Apart from the 2 confounders data subset and parity, the final model contained 4 factors pertaining to lying comfort (abnormal behavior, stall base, head lunge impediment, and neck rail-curb diagonal) and one metabolic factor (BCS). It had the form of

$$
\begin{aligned}
& \ln [p /(1-p)]_{\mathrm{ijklmnop}}=\mu+\beta_{\mathrm{i}} \text { DATA SUBSET }+\beta_{\mathrm{j}} \\
& \text { PARITY }+\beta_{\mathrm{k}} \text { ABNORM }+\beta_{1} \text { STALLBASE }+\beta_{\mathrm{m}} \\
& \text { LUNGEIMP }+\beta_{\mathrm{n}} \text { NRDIAG }+\beta_{\mathrm{o}} \text { BCS }+\varepsilon_{\mathrm{ijklmnop}},
\end{aligned}
$$

where $p=$ probability of cow $\mathrm{p}$ being lame in DATA SUBSET i, PARITY $\mathrm{j}$, abnormal lying behavior (ABNORM) k, freestall base (STALLBASE) l, head lunge impediment (LUNGEIMP) m, neck rail-curb diagonal (NRDIAG) n, body condition score (BCS) o, and error term $(\varepsilon)$ ijklmnop; $\mu=$ intercept; $\beta_{\mathrm{i}}$ to $\beta_{\mathrm{o}}=$ estimates for variables $X_{i}$ to $X_{0}$, respectively.

Risk for lameness increased with decreasing lying comfort, that is, more frequent abnormal lying behavior, mats or mattresses used as a stall base compared with deep-bedded stall bases, the presence of head lunge impediments, or neck rail-curb diagonals that were too short (Table 5). High-parity cows as well as cows in the lowest BCS quartile (BCS from 1.25 to 2.50 in HF and 2.50 to 3.50 in FV) generally had a distinctly higher risk of being lame. Factors abnormal lying behavior, BCS, stall base, and parity were highly significant in the MOD calculation $\left(P_{\text {Wald }}<0.001\right)$. Neck rail-curb diagonal and head lunge impediment were the least significant factors ( $P_{\text {Wald }}=0.017$ and 0.034 , respectively). Wald statistics based on sample VAL were much lower. 
Table 4. Overview of statistically examined risk variables, grouped to logical clusters, for lameness in 3,258 cows from 103 loose-housing dairy farms in Austria and Germany

\begin{tabular}{|c|c|}
\hline Logistical cluster & Risk variable \\
\hline Lying & $\begin{array}{l}\text { Bedding height: } ;^{1} \text { bedding height }<2 \mathrm{~cm} \text {; cow:stall ratio; stall length; height underneath stall partition; curb height; head lunge } \\
\text { impediment: }{ }^{2} \text { lying area length: }{ }^{3} \text { neck rail height; neck rail-curb diagonal; softness of lying area }{ }^{4} \text { type of stall base }\end{array}$ \\
\hline Walking & $\begin{array}{l}\text { Cow:feeding space ratio; dead ends; }{ }^{6} \text { flooring grip; flooring quality; }{ }^{2} \text { loafing area per cow, including outdoor loafing area }\left(\mathrm{m}^{2}\right) \text {; loafing area } \\
\text { per cow in barn only }\left(\mathrm{m}^{2}\right) \text {; rough flooring; automatic manure scraper; slippery flooring; solid vs. slatted flooring; steps in walking area }\end{array}$ \\
\hline Peripartal period & $\begin{array}{l}\text { Calf separated immediately from dam; duration of calf-dam contact }(\mathrm{h}) ;^{7} \text { use of a calving pen; cow immediately removed } \\
\text { from calving pen (i.e., moved back in herd); duration of stay in calving pen after parturition }(h)^{7}\end{array}$ \\
\hline Metabolic supply & Kilograms of concentrate fed per kilogram of milk (farm mean); method of feeding concentrate \\
\hline Management & $\begin{array}{l}\text { Calculations of feed rations; cows in heat free in herd; fixation of cows after milking; injurious equipment in leg reach; herd size; } \\
\text { outdoor loafing area access } ;^{9} \text { pasture access; proportion of farm income derived from dairy; sanitary concerns }{ }^{10}\end{array}$ \\
\hline Animal & Fat-protein-corrected 305-d milk yield; parity \\
\hline Rearing & Introduction of heifers single vs. in groups \\
\hline Other & Data subset \\
\hline Animal-based parameters & $\begin{array}{l}\text { Lying: abnormal behavior related to lying; }{ }^{11} \text { duration of lying-down movements (s). Metabolic supply: BCS; }{ }^{12} \text { BCS range }(\min \text { to max) } \\
\text { on farm; fat:protein ratio out of recommended range }{ }^{2} \text { milk protein content lower than recommended } ;{ }^{2} \text { milk protein content out } \\
\text { of recommended range } ;^{2} \text { milk urea content out of recommended range. }{ }^{2} \text { Metabolic supply: dirtiness of cow; } ;{ }^{13} \text { fearfulness of herd }{ }^{14}\end{array}$ \\
\hline
\end{tabular}

${ }^{1}$ Categorical based on quartiles.

${ }^{2}$ See text for definitions.

${ }^{3}$ From end of stall and inner side of curb to brisket board and front end of stall.

${ }^{4}$ Farm median based on subjective 3-score key involving dropping on knees.

${ }^{5}$ Hard or soft rubber mat or comfort mattress vs. bedded concrete vs. straw-manure mattress.

${ }^{6} \mathrm{At}$ least 1 dead end $(<3 \mathrm{~m}$ wide and $>3 \mathrm{~m}$ deep alley) present on farm.

${ }^{7} 0 \mathrm{~h}$ vs. $>0$ to $12 \mathrm{~h}$ vs. $>12 \mathrm{~h}$; until next milking $=6 \mathrm{~h}$; until cow is fit $=12 \mathrm{~h}$.

${ }^{8} \mathrm{Fed}$ by hand or other vs. fed using transponder in feeder or TMR.

¿ $\quad{ }^{9}$ Year-round outdoor loafing area access for $24 \mathrm{~h} / \mathrm{d}$ vs. no access.

${ }^{10}$ Old manure, for example.

을 ${ }^{11}$ Average frequency/cow in $2 \mathrm{~h}$.

${ }^{12}$ Five-score key with 0.25 -unit intervals; categorical based on quartiles by breed.

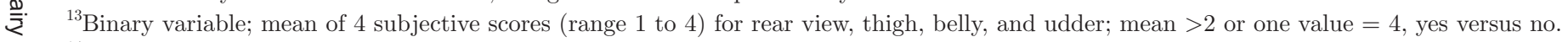

오. ${ }^{14}$ Subjective herd score from 1 (bold) to 3 (timid). 
Parity was still highly significant, with $P_{\text {Wald }}<0.001$, followed by abnormal lying behavior $\left(P_{\text {Wald }}=0.013\right)$. None of the other variables were significant at the $P_{\text {Wald }}$ $\leq 0.05$ level. Only 2 out of 15 significant odds ratios (OR) changed direction when calculated on the smaller sample. They belonged to the 2 variables with the highest $P$-values in the model, neck rail-curb diagonal and head lunge impediment. No OR with a $P$-value $<0.01$ changed direction.

The model had an exchangeable GEE working correlation of 0.059 when calculated on sample MOD. At an estimate probability cutpoint of 0.5 , the proportion of correctly classified observations (PCCO) was $71 \%$ and model sensitivity (Se) and specificity (Sp) were 0.33 and 0.90 , respectively (Table 6 ; receiver operating characteristic curve shown in Figure 1).

The PCCO, Se, Sp, positive predictive value (PPV), and negative predictive value (NPV) at cutpoint 0.5 were virtually identical during cross-validation. The largest difference occurred for Se, which was 0.33 in the MOD and 0.38 in the VAL calculation.

\section{DISCUSSION}

\section{Lying Comfort}

The association between reduced lying comfort and higher lameness risk has also been shown in other onfarm investigations (Mülleder and Waiblinger, 2004; Espejo and Endres, 2007). Assessing the combined effect of freestall factors on the transition between lying and standing (such as dimensions, size of animals on the farm, slipperiness of lying area, and so on) usually requires a sophisticated investigation. Behavioral alterations of the type we used in the factor abnormal lying behavior not only integrated those effects into one measure, but proved to be a reliable indicator of risk for lameness in our investigation. The lack of collinearity between the lying behavior and cubicle parameters can be explained by the fact that the expressed behavior integrates more stall and animal characteristics (e.g., animal size) than we included in the analysis.

There is a possible reversed causation between abnormal lying behavior and lameness because severe lameness can also cause abnormal or prolonged lyingstanding transitions. It would have been more accurate to exclude lame cows from lying behavior observations, but prestudies showed that lying behavior observations with animal identification were not feasible because of visibility and time constraints. However, because the average prevalence of severe lameness in the data set was numerically rather low (16\%), the observed behavior can essentially be regarded as an indicator for uncomfortable stall design.
Risk for lameness was more than twice as high in farms with more frequent abnormal lying behaviors than on the average farm, with very similar significant OR during cross-validation. Results to this effect have also been found by Faull et al. (1996) and in data subset A alone (Dippel et al., 2009). According to Mülleder and Waiblinger (2004), one of the crucial triggers for abnormal lying behavior is short freestall length, which impinges on head lunge space and thus hinders lyingstanding transitions. This agrees with our result of an increased lameness risk on farms with a head lunge impediment. However, the OR for head lunge impediment was not very high and did not stay significant in cross-validation. Besides a possible lack in statistical power, there might be 2 reasons for this. First, our threshold of at least 1 sampled stall having an impediment might have been too strict. And second, it is just one among many factors that influences lying behavior. If head lunge is impeded, it might be balanced by, for example, wider stalls (Tucker et al., 2004). The same applies to neck rail-curb diagonal. Consequently, integrative animal-based parameters such as abnormal lying behavior are preferable to single-stall measures.

Cows not only prefer to lie on soft, deep-bedded stall bases rather than on commercial mattresses, but they also lie down for longer periods of time on deep bedding (Tucker and Weary, 2004). Again, the resulting lying times are likely to have an effect on lameness, which is reflected in various on-farm surveys (Bergsten, 1994; Espejo et al., 2006). Likewise, in the present study, risk for lameness was increased on farms that used rubber mats or cow mattresses as stall bases as opposed to straw-manure mattresses or bedded concrete. Bedded concrete was comparable to straw-manure mattresses because the bedding was usually deep enough to provide cushioning. In data subset $\mathrm{A}$ alone, the proportion of cows that were lying compared with the number of cows using a stall in some way (lying, standing in the stall, standing half in the stall) was also a good predictor for lameness risk (Dippel et al., 2009). However, we were not able to test it in this analysis because of an insufficient number of valid observations in one data subset.

\section{Metabolism}

We chose to use animal-based parameters, rather than laborious and expensive feed analyses, as problem indicators. Of these and the additional feeding management characteristics, only BCS predicted lameness risk across all farms. Cows in the first BCS quartile had the highest risk of being lame, which has also been observed by Espejo et al. (2006). Espejo and colleagues concluded that the low body condition was a result of lameness. 
Table 5. Comparison of least squares means odds ratios $(\mathrm{OR})$ and step-down Bonferroni-corrected $P$-values for the final model calculated on sample data sets MOD and VAL ${ }^{1}$

\begin{tabular}{|c|c|c|c|c|c|c|c|}
\hline \multirow[b]{2}{*}{ Cluster } & \multirow[b]{2}{*}{ Parameter type } & \multirow[b]{2}{*}{ Factor } & \multirow[b]{2}{*}{ Comparison } & \multicolumn{2}{|c|}{ OR } & \multicolumn{2}{|c|}{$P$-value } \\
\hline & & & & MOD & VAL & MOD & VAL \\
\hline \multirow[t]{9}{*}{ Confounder } & \multirow[t]{3}{*}{ Confounder } & \multirow[t]{3}{*}{ Data subset $^{2}$} & O vs. A & 0.94 & 1.12 & 0.777 & 0.728 \\
\hline & & & G vs. A & 1.67 & 2.37 & 0.020 & 0.027 \\
\hline & & & G vs. O & 1.78 & 2.11 & 0.011 & 0.097 \\
\hline & \multirow{6}{*}{ Risk factor } & \multirow{6}{*}{ Parity } & 2 vs. 1 & 1.49 & 1.33 & 0.011 & 0.266 \\
\hline & & & 3 vs. 1 & 1.74 & 2.26 & 0.002 & 0.013 \\
\hline & & & 3 vs. 2 & 1.17 & 1.69 & 0.253 & 0.113 \\
\hline & & & $4+$ vs. 1 & 3.25 & 4.57 & $<0.001$ & $<0.001$ \\
\hline & & & $4+$ vs. 2 & 2.19 & 3.43 & $<0.001$ & $<0.001$ \\
\hline & & & $4+$ vs. 3 & 1.87 & 2.03 & $<0.001$ & 0.023 \\
\hline \multirow[t]{7}{*}{ Lying comfort } & Animal-based & $\begin{array}{l}\text { More frequent abnormal lying behavior than the average } \\
\text { over all farms }{ }^{3} \text { (yes vs. no) }\end{array}$ & & 2.25 & 2.17 & 0.000 & 0.013 \\
\hline & \multirow[t]{4}{*}{ Risk factor } & Stall base & & & & & \\
\hline & & Bedded concrete vs. mat or mattress & & 0.47 & 0.73 & $<0.001$ & 0.743 \\
\hline & & Straw-manure mattress vs. mat or mattress & & 0.37 & 0.92 & $<0.001$ & 0.760 \\
\hline & & Straw-manure mattress vs. bedded concrete & & 0.78 & 1.26 & 0.191 & 0.817 \\
\hline & Risk factor & Head lunge impediment ${ }^{4}$ (yes vs. no) & & 1.38 & 0.82 & 0.034 & 0.396 \\
\hline & Risk factor & Heck rail-curb diagonal too short ${ }^{4}$ (yes vs. no) & & 1.43 & 0.94 & 0.017 & 0.797 \\
\hline \multirow{6}{*}{ Metabolism } & \multirow[t]{6}{*}{ Animal-based } & \multirow[t]{6}{*}{ BCS, quartiles by breed ${ }^{5}$} & second vs. first & 0.66 & 0.57 & 0.002 & 0.229 \\
\hline & & & third vs. first & 0.48 & 0.65 & $<0.001$ & 0.746 \\
\hline & & & third vs. second & 0.73 & 1.13 & 0.104 & 1.000 \\
\hline & & & fourth vs. first & 0.51 & 0.53 & $<0.001$ & 0.189 \\
\hline & & & fourth vs. second & 0.77 & 0.93 & 0.078 & 0.770 \\
\hline & & & fourth vs. third & 1.05 & 0.82 & 0.712 & 1.000 \\
\hline
\end{tabular}

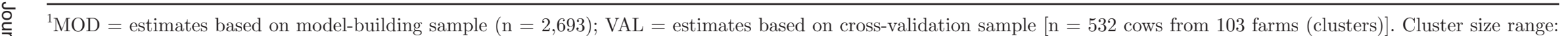
MOD $=16-42, \mathrm{VAL}=3-8$. Mean lameness prevalence: $\mathrm{MOD}=33 \%, \mathrm{VAL}=36 \%$.

$\stackrel{2}{\circ} \mathrm{A}=$ Austria, Fleckvieh, conventional; $\mathrm{O}=$ Germany, Holstein-Friesian, organic; $\mathrm{G}=$ central Germany, Holstein-Friesian, conventional.

o ${ }^{3}$ Average frequency/cow in $2 \mathrm{~h}$.

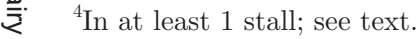

ก). $\quad{ }^{5}$ First $=$ lowest BCS quartile (thin cows), fourth = highest (fat cows); see text. 


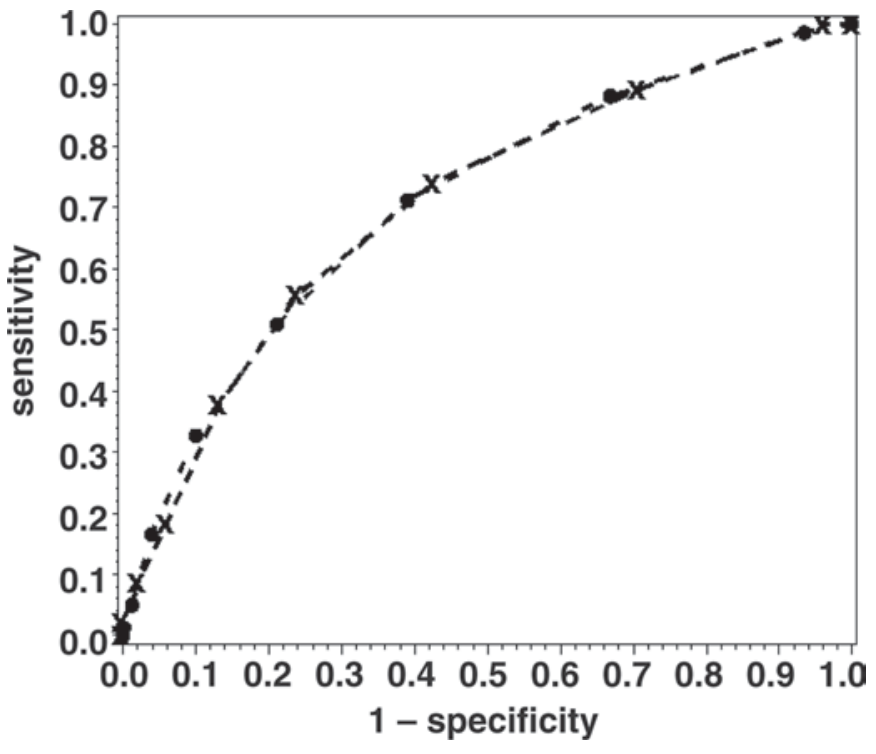

Figure 1. Receiver operating characteristic (ROC) curves based on 11 probability cutpoints ( 0.0 to 1.0 with 0.1 increments). $\bullet=$ model based on model-building sample (MOD), $\times=$ model based on crossvalidation sample (VAL).

They based their conclusion on the negative association between body condition and lameness score observed by Manson and Leaver (1989), as well as the shorter feeding times in lame animals found by Winckler and Brill (2004). Nevertheless, low body condition may also be a risk factor for, rather than a result of, lameness. First, feeding time is not always reduced by lameness (Singh et al., 1993). Second, DMI decreases only in severely lame cows (Bach et al., 2007), which in data subsets $\mathrm{A}$ and $\mathrm{O}$ were not very prevalent [prevalence of severe lameness (scores 4 and 5 ) in data subset $\mathrm{A}=12 \%, \mathrm{O}$ $=11 \%$, and $\mathrm{G}=26 \%$ ]. On the other hand, low body condition predisposes cows to ketotic conditions, par- ticularly at the start of lactation. This in turn reduces the function of the digital cushion, thereby facilitating damage to the corium (Mülling and Greenough, 2006). Because all HF cows in the first BCS quartile were underconditioned (according to the limits suggested by Metzner et al., 1993), we very likely observed the effect of body condition on lameness rather than vice versa.

Usually, increased risk for lameness is also proposed for high-condition cows as a result of overconditioning at dry-off (Gearhart et al., 1990) or higher loads on the claws (Wells et al., 1993). This was not obvious in the present study; the reason probably differs for each breed. Only $3.27 \%$ of all HF cows had BCS higher than the recommended maximum of 3.75 (Metzner et al., 1993), yet the fourth quartile contained $15 \%$ of all $\mathrm{HF}$ cows. Thus, the highest quartile did not represent overconditioned cows. By contrast, in FV cows the fourth quartile did represent cows considered to be overconditioned (Jilg and Weinberg, 1998), but FV represents a dual-purpose breed for which high BCS may have less effect on lameness. Moreover, FV accounted for only $27 \%$ of all cows in the model.

\section{Parity}

The strong influence of parity number agrees with other studies in this field (e.g., Groehn et al., 1992) and was established in data subset A alone (Dippel et al., 2009). Higher risk for lameness in first-parity cows caused by the combined effects of physiological, housing, and management changes around the time of parturition has been described (Bergsten, 1994). However, our result of increasing lameness risk with increasing parity number is a more consistent finding in the literature (Groehn et al., 1992; Espejo et al., 2006). The main reason for this is accumulated susceptibility: cows that

Table 6. Cross-validation of model predictive ability at different probability cutpoints for collapsing estimates into 0 and 1 (estimate smaller or larger than cutpoint, respectively) ${ }^{1}$

\begin{tabular}{|c|c|c|c|c|c|c|c|c|c|c|}
\hline \multirow{2}{*}{$\begin{array}{l}\text { Probability } \\
\text { cutpoint }\end{array}$} & \multicolumn{2}{|c|}{$\mathrm{PCCO}$} & \multicolumn{2}{|c|}{$\mathrm{Se}$} & \multicolumn{2}{|c|}{$\mathrm{Sp}$} & \multicolumn{2}{|c|}{ PPV } & \multicolumn{2}{|c|}{ NPV } \\
\hline & MOD & VAL & MOD & VAL & MOD & VAL & MOD & VAL & MOD & VAL \\
\hline 0.10 & 0.36 & 0.37 & 0.99 & 1.00 & 0.06 & 0.04 & 0.34 & 0.36 & 0.91 & 1.00 \\
\hline 0.20 & 0.51 & 0.50 & 0.88 & 0.89 & 0.33 & 0.29 & 0.39 & 0.40 & 0.85 & 0.84 \\
\hline 0.30 & 0.64 & 0.63 & 0.71 & 0.74 & 0.61 & 0.57 & 0.47 & 0.48 & 0.81 & 0.81 \\
\hline 0.40 & 0.70 & 0.69 & 0.51 & 0.56 & 0.79 & 0.76 & 0.54 & 0.55 & 0.77 & 0.76 \\
\hline 0.70 & 0.68 & 0.67 & 0.05 & 0.09 & 0.99 & 0.98 & 0.66 & 0.70 & 0.68 & 0.67 \\
\hline 0.80 & 0.68 & 0.66 & 0.01 & 0.02 & 1.00 & 1.00 & 0.79 & 1.00 & 0.68 & 0.66 \\
\hline 0.90 & 0.67 & 0.65 & 0.00 & 0.00 & 1.00 & 1.00 & - & - & 0.67 & 0.65 \\
\hline 1.00 & 0.67 & 0.65 & 0.00 & 0.00 & 1.00 & 1.00 & - & - & 0.67 & 0.65 \\
\hline
\end{tabular}

${ }^{1} \mathrm{PCCO}=$ proportion of correctly classified observations; Se = sensitivity; $\mathrm{Sp}=$ specificity; PPV = positive predictive value; NPV $=$ negative predictive value; $\mathrm{MOD}=$ estimates based on model-building sample; VAL = estimates based on cross-validation sample. 
have been lame are at a higher risk of becoming lame again than healthy cows (Hirst et al., 2002).

\section{Analysis}

Model sensitivity might have been improved had we investigated separate claw lesions such as sole ulcer or white line disease instead of the general parameter lameness. Risk factors for single lesions are more specific than the broad spectrum of lameness risk factors and thus are easier to determine. However, there are 3 arguments for investigating lameness. First, the relevance of single lesions for the animal could not yet clearly be determined (Flower and Weary, 2006), whereas lameness has been established as a painful condition (Whay et al., 1997). In addition, lameness restricts the natural expression of behavior, as in the previously mentioned reduced feeding times in severely lame cows (Bach et al., 2007). Last, there are practical constraints to claw lesion investigations. Farm records of lesion treatments are not a reliable source of data because farms differ in treatment protocols as well as in recordkeeping quality. Also, collecting standardized records of claw lesions in an on-farm survey is far more time consuming and expensive than recording lameness prevalences.

Model predictive ability in general was high with $71 \%$ correctly classified observations. Sensitivity, Sp, PPV, and NPV were also high, especially in the face of the complex nature of lameness causation. Furthermore, the model was reliable, as PCCO, Se, Sp, PPV, and NPV changed only little during cross-validation. The high predictive ability of abnormal lying behavior for lameness was confirmed by cross-validation, yet, other than this factor, only confounders stayed significant in the VAL calculation (Wald statistic). This could have been caused by the limited size of the cross-validation sample.

The major limitations of our study are, from a statistical point of view, the limited number of farms in the data set and its cross-sectional characteristic. In cross-sectional studies there can be issues of cause-andeffect (such as for BCS and abnormal lying behavior in this study) and of representativity because data are collected at only one point in time. However, we strove to maximize representativity by sampling only barns that had been in use for at least 1 yr with the current fittings and choosing animal-based parameters that are comparatively stable over time (e.g., milk compounds). In addition, we are positive to have solved the causeand-effect problems of BCS and of abnormal lying behavior at a satisfactory level based on additional information in the data set.

\section{CONCLUSIONS}

Lying comfort is a risk factor that strongly affects lameness in dairy cows across 2 breeds, 2 different farming systems, and 2 European countries. Abnormal lying behavior proved to be a good predictor of lameness risk and may thus aid in risk factor identification on dairy farms.

\section{ACKNOWLEDGMENTS}

We thank the participating farmers for their time, interest, and generous hospitality. The performance recording agencies and breeding associations of Lower Austria, Upper Austria, Styria, Baden-Wuerttemberg, Bavaria, North Rhine-Westphalia, Schleswig-Holstein, and VIT Verden, as well as Christian Fürst from ZuchtData (Vienna, Austria), are appreciated for their help with farm selection and milk performance data. Data subset $\mathrm{O}$ was funded by the German Federal Organic Farming Scheme, Work Package 03OE406Animal health in the food chain management in organic dairy farming. The present study is part of the Welfare Quality research project, which has been cofinanced by the European Commission within the 6th Framework Programme, contract No. FOOD-CT-2004-506508. The text represents the authors' views and does not necessarily represent a position of the Commission, who will not be liable for the use made of such information.

\section{REFERENCES}

Amory, J. R., Z. E. Barker, J. L. Wright, S. A. Mason, R. W. Blowey, and L. E. Green. 2008. Associations between sole ulcer, white line disease and digital dermatitis and the milk yield of 1824 dairy cows on 30 dairy cow farms in England and Wales from February 2003-November 2004. Prev. Vet. Med. 83:381-391.

Bach, A., M. Dinares, M. Devant, and X. Carre. 2007. Associations between lameness and production, feeding and milking attendance of Holstein cows milked with an automatic milking system. J. Dairy Res. 74:40-46.

Bell, N. J., D. C. J. Main, H. R. Whay, T. G. Knowles, M. J. Bell, and A. J. F. Webster. 2006. Herd health planning: Farmers' perceptions in relation to lameness and mastitis. Vet. Rec. 159:699-705.

Bennett, R. M., K. Christiansen, and R. S. Clifton-Hadley. 1999. Estimating the costs associated with endemic diseases of dairy cattle. J. Dairy Res. 66:455-459.

Bergsten, C. 1994. Haemorrhages of the sole horn of dairy cows as a retrospective indicator of laminitis: An epidemiological study. Acta Vet. Scand. 35:55-66.

Brenninkmeyer, C., S. Dippel, S. March, J. Brinkmann, C. Winckler, and U. Knierim. 2007. Reliability of a subjective lameness scoring system for dairy cows. Anim. Welf. 16:127-129.

Brinkmann, J., and C. Winckler. 2004. Influence of the housing system on lameness prevalence in organic dairy farming. Pages 166-167 in Proc.13th Int. Symp. and 5th Conference on Lameness in Ruminants, 11. Feb. 15, 2004, Maribor, Slovenia.

Cook, N. B. 2005. Wie gut sind Ihre Liegeboxen? Elite 3:44-47.

Dippel, S., M. Dolezal, C. Brenninkmeyer, J. Brinkmann, S. March, U. Knierim, and C. Winckler. 2009. Risk factors for lameness in 
cubicle housed Austrian Simmental dairy cows. Prev. Vet. Med. 90:102-112.

Dohoo, I. R., W. Martin, and H. Stryhn. 2003. Veterinary Epidemiologic Research. AVC Inc., Charlottetown, Prince Edward Island, Canada.

Espejo, L. A., and M. I. Endres. 2007. Herd-level risk factors for lameness in high-producing Holstein cows housed in freestall barns. J. Dairy Sci. 90:306-314.

Espejo, L. A., M. I. Endres, and J. A. Salfer. 2006. Prevalence of lameness in high-producing Holstein cows housed in freestall barns in Minnesota. J. Dairy Sci. 89:3052-3058.

Faull, W. B., J. W. Hughes, M. J. Clarkson, D. Y. Downham, F. J. Manson, J. B. Merritt, R. D. Murray, W. B. Russell, J. E. Sutherst, and W. R. Ward. 1996. Epidemiology of lameness in dairy cattle: The influence of cubicles and indoor and outdoor walking surfaces. Vet. Rec. 139:130-142.

Flower, F. C., and D. M. Weary. 2006. Effect of hoof pathologies on subjective assessments of dairy cow gait. J. Dairy Sci. 89:139146.

Galindo, F., and D. M. Broom. 2000. The relationships between social behaviour of dairy cows and the occurrence of lameness in three herds. Res. Vet. Sci. 69:75-79.

Galindo, F., D. M. Broom, and P. G. G. Jackson. 2000. A note on possible link between behaviour and the occurrence of lameness in dairy cows. Appl. Anim. Behav. Sci. 67:335-341.

Gearhart, M. A., C. R. Curtis, H. N. Erb, R. D. Smith, C. J. Sniffen, L. E. Chase, and M. D. Cooper. 1990. Relationship of changes in condition score to cow health in Holsteins. J. Dairy Sci. 73:31323140 .

Groehn, J. A., J. B. Kaneene, and D. Foster. 1992. Risk factors associated with lameness in lactating dairy cattle in Michigan. Prev. Vet. Med. 14:77-85.

Hernandez-Mendo, O., M. A. G. von Keyserlingk, D. M. Veira, and D. M. Weary. 2007. Effects of pasture on lameness in dairy cows. J. Dairy Sci. 90:1209-1214.

Hirst, W. M., R. D. Murray, W. R. Ward, and N. P. French. 2002. A mixed-effects time-to-event analysis of the relationship between first-lactation lameness and subsequent lameness in dairy cows in the UK. Prev. Vet. Med. 54:191-201.

Jeroch, H., W. Drochner, and O. Simon. 1999. Ernährung landwirtschaftlicher nutztiere: Ernährungsphysiologie, futtermittelkunde, fütterung. Page 439 in Milchkuhfütterung Eugen Ulmer GmbH \& Co., Stuttgart, Germany.

Jilg, T., and L. Weinberg. 1998. Konditionsbewertung: Jetzt auch beim Fleckvieh. Top Agrar 6:R12-R15.

Knott, L., J. F. Tarlton, H. Craft, and A. J. F. Webster. 2007. Effects of housing, parturition and diet change on the biochemistry and biomechanics of the support structures of the hoof of dairy heifers. Vet. J. 174:277-287.

Leonard, F. C.. J. O'Connell, and K. O'Farrell. 1994. Effect of different housing conditions on behaviour and foot lesions in Friesian heifers. Vet. Rec. 134:490-494.

Liang, K. Y., and S. L. Zeger. 1986. Longitudinal data analysis using generalized linear models. Biometrika 73:13-22.

Manske, T., J. Hultgren, and C. Bergsten. 2002. Prevalence and interrelationships of hoof lesions and lameness in Swedish dairy cows. Prev. Vet. Med. 54:247-263.

Manson, F. J., and J. D. Leaver. 1988. The influence of dietary protein intake and of hoof trimming on lameness in dairy-cattle. Anim. Prod. 47:191-199.
Manson, F. J., and J. D. Leaver. 1989. The effect of concentrate-silage ratio and of hoof trimming on lameness in dairy-cattle. Anim. Prod. 49:15-22.

Metzner, M., W. Heuwieser, and W. Klee. 1993. Die beurteilung der körperkondition (body condition scoring) im herdenmanagement. Prakt. Tierarzt 11:991-998.

Mülleder, C., and S. Waiblinger. 2004. Analyse der Einflussfaktoren auf Tiergerechtheit, Tiergesundheit und Leistung von Milchkühen im Boxenlaufstall auf konventionellen und biologischen Betrieben unter besonderer Berücksichtigung der Mensch-Tier-Beziehung. Endbericht zum Forschungsprojekt 1267 (in German). Eigenverlag Wien, Vienna, Austria.

Mülling, C., and P. R. Greenough. 2006. Applied physiopathology of the foot. Pages 103-117 in Proc. World Buiatrics Congress, 15, Nice, France.

Rutherford, K. M. D., F. M. Langford, M. C. Jack, L. Sherwood, A. B. Lawrence, and M. J. Haskell. 2009. Lameness prevalence and risk factors in organic and non-organic dairy herds in the United Kingdom. Vet. J. 180:95-105.

SAS Institute. 2008. SAS OnlineDoc 9.1.3. http://support.sas.com/ onlinedoc/913/docMainpage.jsp. Accessed Apr. 10, 2009.

Singh, S. S., W. R. Ward, K. Lautenbach, and R. D. Murray. 1993 Behaviour of lame and normal dairy cows in cubicles and in a straw yard. Vet. Rec. 133:204-208.

Tucker, C. B., and D. M. Weary. 2004. Bedding on geotextile mattresses: How much is needed to improve cow comfort? J. Dairy Sci. 87:2889-2895

Tucker, C. B., D. M. Weary, and D. Fraser. 2004. Free-stall dimensions: Effects on preference and stall usage. J. Dairy Sci. 87:12081216

Warnick, L. D., D. Janssen, C. L. Guard, and Y. T. Grohn. 2001. The effect of lameness on milk production in dairy cows. J. Dairy Sci. 84:1988-1997.

Webster, A. J. F. 2001. Effects of housing and two forage diets on the development of claw horn lesions in dairy cows at first calving and in first lactation. Vet. J. 162:56-65.

Wells, S. J., A. M. Trent, W. E. Marsh, P. G. McGovern, and R. A. Robinson. 1993. Individual cow risk factors for clinical lameness in lactating dairy cows. Prev. Vet. Med. 17:95-109.

Whay, H. R., A. E. Waterman, and A. J. F. Webster. 1997. Associations between locomotion, claw lesions and nociceptive threshold in dairy heifers during the peri-partum period. Vet. J. 154:155-161.

Winckler, C., and G. Brill. 2004. Lameness prevalence and behavioura traits in cubicle housed dairy herds - a field study. Pages 160161 in Proc.13th Int. Symp. and 5th Conference on Lameness in Ruminants, 11. Feb. 15, 2004, Maribor, Slovenia.

Winckler, C., and U. Knierim. 2004a. Checklisten zur überprüfung der tiergerechtheit im boxenlaufstall. In BpT Fortbildungsveranstaltung Integrierte Tierärztliche Bestandsbetreuung, 16. Apr. 17, 2004, Nürnberg, Germany.

Winckler, C., and U. Knierim. 2004b. Checklisten zur überprüfung der tiergerechtheit im kurzstand-anbindestall. In BpT Fortbildungsveranstaltung Integrierte Tierärztliche Bestandsbetreuung, 16. Apr. 17, 2004, Nürnberg, Germany.

Winckler, C., and S. Willen. 2001. The reliability and repeatability of a lameness scoring system for use as an indicator of welfare in dairy cattle. Acta Agric. Scand. Anim. Sci. 51(Suppl. 30):103-107. 